\title{
HISTORICAL LANDSLIDES IN THE PREFECTURE OF IOANNINA - COLLECTION AND ANALYSIS OF DATA
}

\author{
Kalantzi F. ${ }^{1}$, Doutsou I. ${ }^{2}$, Koukouvelas I. ${ }^{1}$ \\ ${ }^{1}$ University of Patras, Department of Geology, 26500 Patras, Greece, feikal8@yahoo.gr \\ iannis@upatras.gr \\ ${ }^{2}$ Ioanna.doutsou@Kcl.ac.uk
}

\begin{abstract}
The present study assessed landslide events over a time span of fifty years in the prefecture of Ioannina. Historical data analysis commonly provides valuable data for understanding distribution of landslides. The methodology included collection and analysis of articles about landslides events found in the local newspapers between 1960 and 2008, also in the national newspapers (1960-1967) and in the contemporary national newspapers (1995-2008). The time interval selected in this study is representative of the entire time period of systematic newspapers publication. During this time spam, eighty nine historical landslides were identified. Newspaper articles annotate the time and the location of the landslides as well as primarily the role of weather conditions in triggering the landslides. In addition, published articles provide information on the damages caused by the landslides. The study shows that these events occurred due to extremely high precipitation, snowstorms or prolonged rainfall. The monthly distribution of the recorded phenomena shows an increase of landslide events during January-March and November-December, as these are the months with the highest precipitation and snowing in the prefecture. Although time clustering of the landslides within the Ioannina Prefecture in the time interval 1960 to 2006 was found to be repeated every forty years, their spatial clustering appears to change.
\end{abstract}

Key words: landslides, historical data, newspapers, Ioannina

\section{Introduction}

With a direct impact on humans and a number of indirect consequences, landslide events have nowadays been one of the international scientific community's hazards research interests. Landslides in Greece, their triggering mechanisms, their characteristics and restoration projects have been widely assessed and described with the use of statistical analysis by a number of scholars

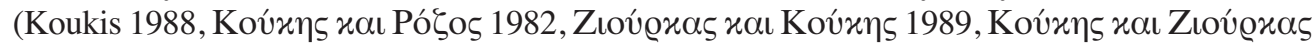
1989, Koukis and Ziourkas 1991, Koukis et al. 1994, Koukis et al 1996, Koukis et al 1997). In this study, we consider the collection of historical data as a necessary process in order to approach landslides phenomena and the vulnerability of the human environment. A wealth of international literature (Dominguez Cuesta et al.1999, Guzzetti et al. 1994, 2002, Calcaterra et al.2003, Carrara et al. 2003, Tropeano and Turconi 2004, Tarhule 2005, Sawyer and Butler 2006, Devoli et al. 2007a and b, Wrathall 2007) has used effectively press reports, databases and articles about landslide events and other natural disasters as valuable sources of information when 


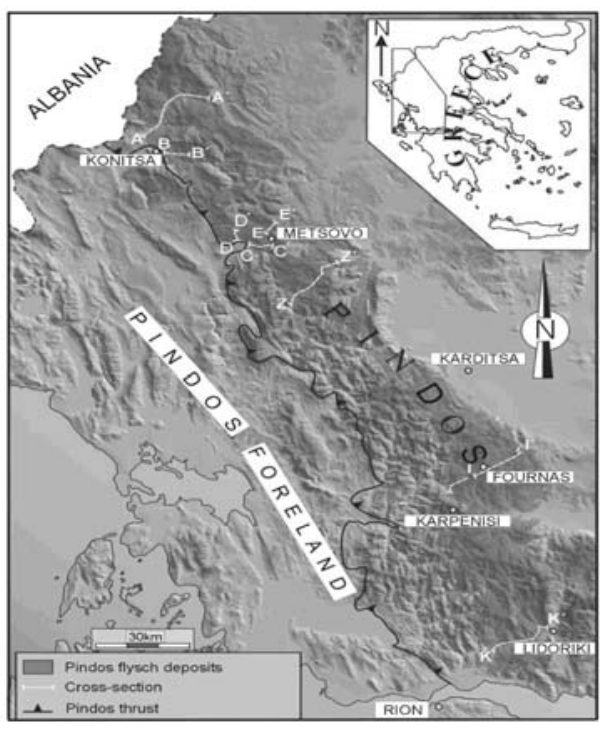

Fig. 1: Digital model of the ground of the Epirus region (http://www.ntua.gr/MIRC/db/epirus_db/ GEOLOGIA_HPEIROY/Geologia_Hpeirou.htm).

compiling scientific accounts of landslides events. In line with this method, this study collects valuable information about the landslides events from a variety of sources such as technical reports, historical monographs, scientific documents, public libraries, internet and newspapers.

Due to a lack of database of recorded landslides events in the prefecture of Ioannina, newspapers represent a valuable source of information not only for the assessment of landslide events but also for the creation of a landslides inventory. Press industry in Greece which firstly appears at the end of the 19th century, is regarded as the first mean for the transmission of news concerning natural hazards and disasters (e.g. landslides, or earthquakes). The present study focuses on landslide events recorded between 1960 and 2008. Relevant information on landslide events has been obtained using newspapers as main sources to investigate temporal and spatial distribution, types of landslides, and their triggering mechanisms in the prefecture of Ioannina.

\section{Study Region}

The prefecture of Ioannina belongs in the region of Epirus (Fig.1) with an estimated population of 175,000 . With an area of $4,990 \mathrm{~km}^{2}$ (http://medlab.cs.uoi.gr), the prefecture of Ioannina is one of the largest and mountainous prefecture in Greece (www.epirus.gov.gr.). In Easterly, the prefecture's natural border constitutes of the mountain range of Pindos, while centrally are found the mountainous groups of Zagori and Mitsikeli. Mountain ranges of the prefecture include Kasidiaris, Kourenton, Douskos and Mourgana in the western and Souli and Tomaros in the south. The climate of Ioannina is continental with an average temperature of around 6,1 ${ }^{\circ} \mathrm{C}$. The annual rainfalls vary, ranging between 1.000 and $2.000 \mathrm{~mm}$ (www.hnms.gr).

The Ioannina Prefecture is geologically extended from the Mesohellenic Trough in the east to the frontal parts of the Ionian zone in the west (Doutsos et al. 2006). Three major structural provinces can be distinguished in this section: (1) the Mesohellenic Trough; (2) the Pindos fold-and-thrust belt; and (3) a broadly spaced array of thrusts within the Ionian zone in the west (Fig. 2). The Mesohellenic Trough is primarily floored by the Pindos ocean ophiolitic rocks and is filled by the Middle Eocene flysch and Oligocene to Lower Miocene molasse sediments (Fig. 


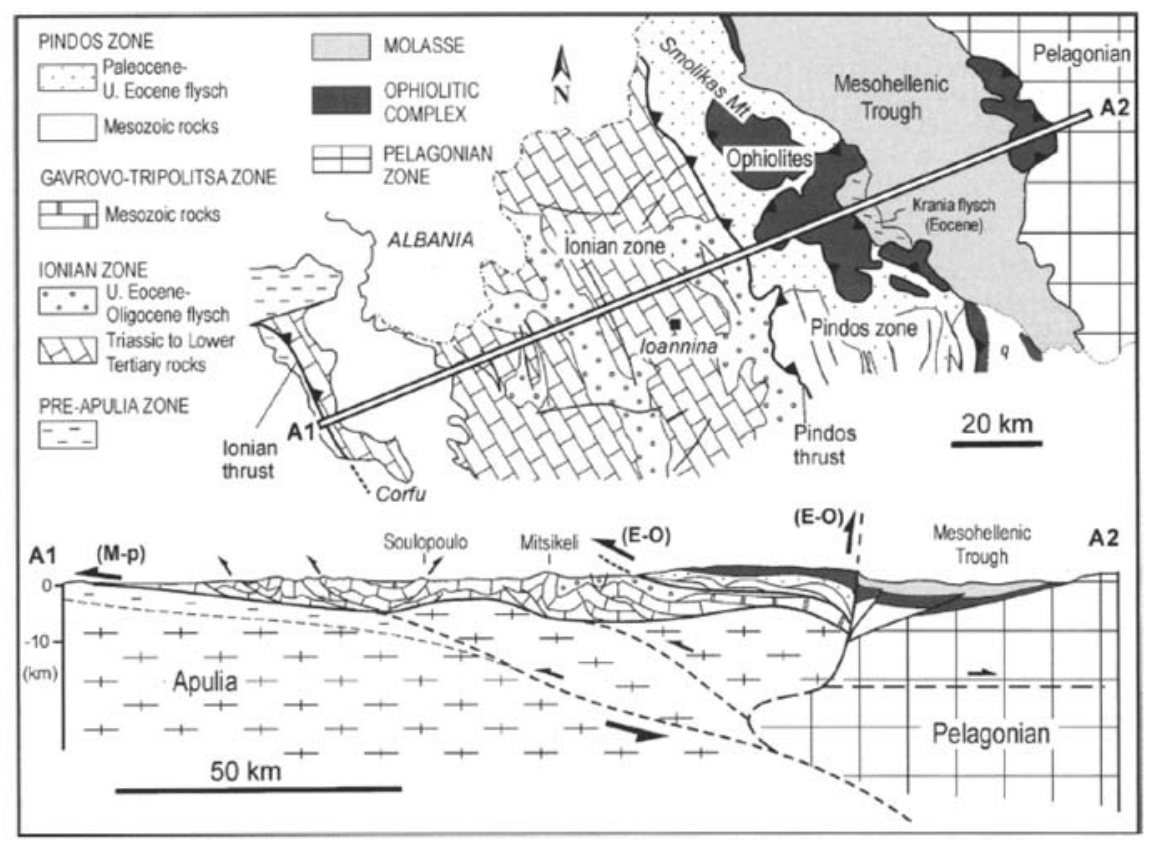

Fig. 2: Tectonic map of Ioannina area and their surroundings (adapted from Doutsos et al. 2006).

2) (Doutsos et al. 1994, 2006). At the western border of the Mesohellenic Trough a high-angle reverse fault carries the ophiolitic rocks over the Pindos zone flysch (Fig. 2). The area west of the Mesohellenic Trough to the west border of the Ioannina prefecture is mainly occupied by calcareous rocks of the Ionian zone and two main flysch basins, the Pindos and Ionian (Xypolias and Koukouvelas 2005). The deformation in this area appears to be significant, involving flysch-filled piggyback basins in the east and a system of thrust faults to the west that caused steep slopes and intense fracturing of the rocks in the area under study.

\section{Methodology}

The present study relies on a database of all possible documents describing landslides events which occurred between 1960- 2008. Firstly, we collected information from public archives, historical monographs and technical reports. As the amount of data collected from these sources regarding the initial research period was insufficient, there was a follow up research in newspaper texts. More specifically, all newspapers were manually read and searched chronologically starting from 1960. The information was collected by copying the originals texts or copying only the most important sentences regarding landslides (i.e., title of the news or the text below photos). Subsequently, the landslide events were categorized according to their spatial and temporal distribution as well as their triggering mechanisms. Internet sources were used as well. Technical reports referring to landslide events helped us to cross-check the newspaper reports.

The local newspapers "Proinos Logos" and "Hpeirotikos Agonas" were the main newspaper used as sources of information for this study. Occasionally, the newspaper articles included photos. A total of 89 articles that recorded landslides were found, mainly in the Zosimaia Public Central Historical Library. Additional sources used for the study were the digital online 
archive of the national newspaper "Eleftheria" referring to 1960-1967 and other contemporary national newspapers ("Ethnos" 2005-2008, "Eleftherotipia" 2001-2008, "Kathimerini" 20012008, "Rizospastis" 1995-2008, “To Vima” 2001-2008 and "Ta Nea” 2001-2008). Sources from local authorities such as the Greek Institute of Geology and Mineral Exploration (Preveza Branch) and the Director's Office of Technical Services of the Ioannina's prefecture have also been used but not thoroughly investigated.

\section{Types of data and limitations}

From the 89 historical landslide events found in different sources, 91\% was obtained from newspapers, $9 \%$ from technical reports scientific papers and other sources (monographs, books, or web pages). Nine different newspapers were consulted and 98 articles were found describing landslide processes. "Proinos Logos" newspaper provided the largest number of records followed by "Hpirotikos Agonas".

Based mainly on data extracted from the newspapers, landslides' descriptions in the press appear to have some common characteristics. How do these stories describe the landslide events and in what features of their occurrence do they rely on? To this end, textual analysis based on newspaper stories produced the following coding categories which reflect the characteristics of the press coverage and at the same time provide valuable information about the landslides occurrence: a) temporal information b) spatial information c) descriptions of the event and implications d) triggering mechanisms e) estimations about future activities f) sources of information and their reliability.

However, there were certain considerations about the obtained data that affect the study's results. Newspapers usually reported the date of the event although occasionally without specifying the exact temporal information (e.g. "last week"). Spatial information about landslide events was variable. The newspaper sources usually provided information on the locality affected, but do not provide information on the source area. In some cases, places reported names of streets, roads, villages and mountains- could not be located in current topographic maps as they have changed throughout time. For this reason, it was difficult in these particular cases to locate the exact place of landslide events in the topographic map. In cases that the places reported were not recognizable, landslides' locations were assigned based on interviews with aged people or our own knowledge of the area.

Temporal information and data on the location of the landslide events are also variable, being extremely detailed in some cases -especially in contemporary descriptions- and rather uncertain in others. The size of the landslide is usually not recorded, but sometimes it is given in a qualitative way. Here are some examples (Figs. 3 and 4): "Strong Earthquake Shaking was felt in Konitsa" during the shaking individual boulders fall down slopes in the Aoos Gorge and "Landslides triggered in an area of approximately 2,500 sq. m. However, what cause fear are wet sliding masses (probably the reporter is referred to debris flows during the earthquake) that devastated everything down the slope from Profitis Ilias summit covering vegetated areas too. In addition it is remarkable and horrible the dense array of scars on the slope".

Also, the reliability of available data had to be carefully considered as it was not possible to evaluate the validity and accuracy of information presented in the articles. The ability of the press to reconstruct an event and mislead public opinion has always been a concern for media scholars. In this study, inaccuracies regard landslide's dimension and their threat evaluation. In 


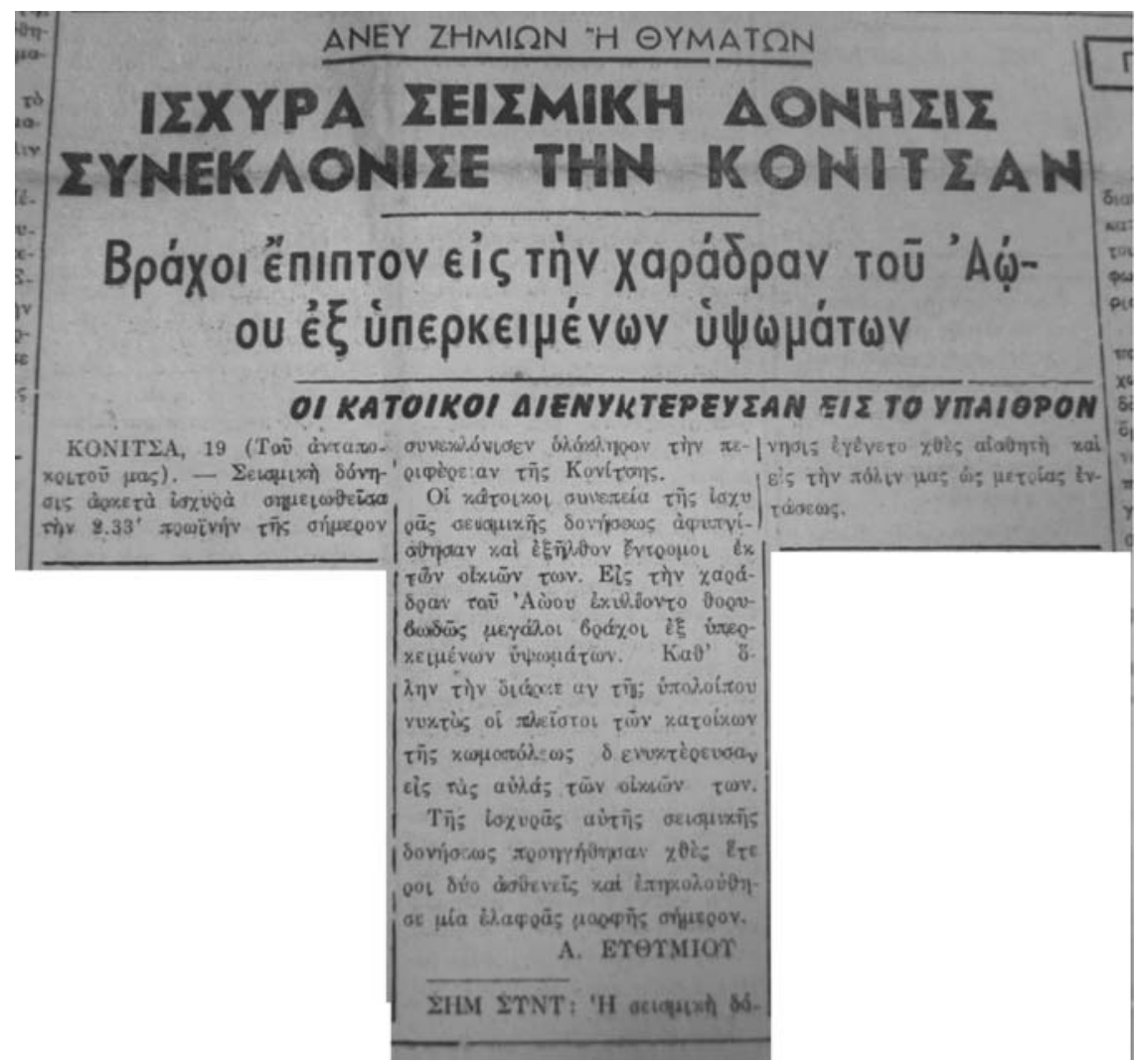

Fig. 3: Headline of newspaper "Proinos Logos", Auguts 19, 1960 recording earthquake triggered landslides.

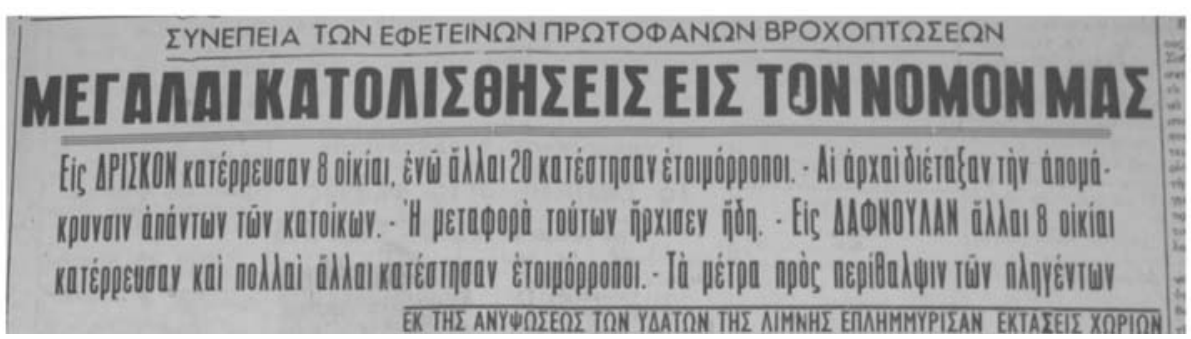

Fig. 4: Head line news from Proinos Logos 22 January 1963.

some cases, stories lack scientific resources and as a result reproduce misleading estimations of the hazards, rumours and overestimations of the situation. Such journalistic practices are particularly evident in contemporary reporting.

Nevertheless, newspapers through publishing technical reports and scientific information written from specialists and adapted to public knowledge help people understand the landslide hazards and the possible solutions of the problems revealed and in this case newspapers offer significant data (e.g. the newspaper article by Koukis, Eleftherotipia 04/01/2006). 


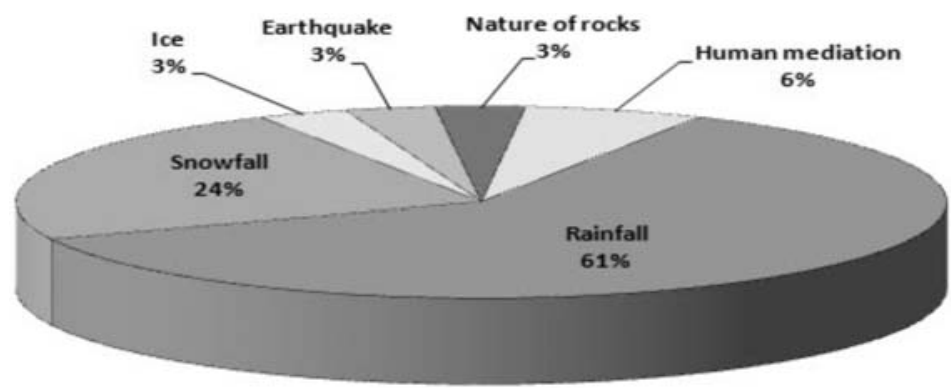

Fig. 5. Most common triggering mechanisms for recorded historical landslides.

When more than one source was available for the same landslide event, the data were extracted from those sources that were judged to be the best documented or most reliable. In case of multiple sources, we selected the cross-examination of the sources adopting the most conservative descriptions.

\section{Results}

Landslide events occurring in the region of Ioannina are mostly a topic of the local press and it is only the major landslides events that they appear in the national press. After having obtained a large database of the articles corresponding to a large time span of 60 years, articles were analyzed both quantitatively and in qualitative terms and provided useful information about landslides events and the way they gain publicity.

\subsection{Landslides' triggering mechanisms}

The major percentage (88\%) of the landslide events in the prefecture takes place after extreme physical phenomena (heavy rainfall, snowfall and ice)(Figs. 4 and 5). According to the statistic analysis of 800 cases of landslide events in Greece, the mean annual rainfall height corresponding to the landslide areas is $1164,8 \mathrm{~mm}$ while for $50 \%$ of the cases $1090 \mathrm{~mm}$ (Koukis 1988; Koukis and Ziourkas 1991). Also the relative frequency of landslides and the mean annual rainfall height is connected through an exponential relationship (Koukis, 1988). Our results are in accordance with these studies as the landslide events under study occur due to extreme physical phenomena such as heavy and continuous rain, snowfall, ice and strong wind. Specifically accrding to the press reports landslides triggered by rainfall correspond to $62 \%$, these related with snowfall to $23 \%$ and ice $3 \%$ (Fig. 5). Rainfalls are the most frequent triggering mechanism of the historical landslides recorded. Although landslides have occurred throughout the year, their monthly distribution clearly shows an increment in the number of events during the period from January-March and November-December (Fig. 6). These time periods seem to be the months with the major rainfall percentage in the prefecture.

The time period between the rainfall and the landslide event was about 2 - 3 days. In minor percentages the landslide events were due to other causes (e.g. earthquakes). Still, someone could consider the human factor, which can act upon the site or the extent of the landslide event.

\subsection{Landslides' temporal and spatial distribution}

Newspaper sources provided a rich database of spatial information about the occurrence of land- 


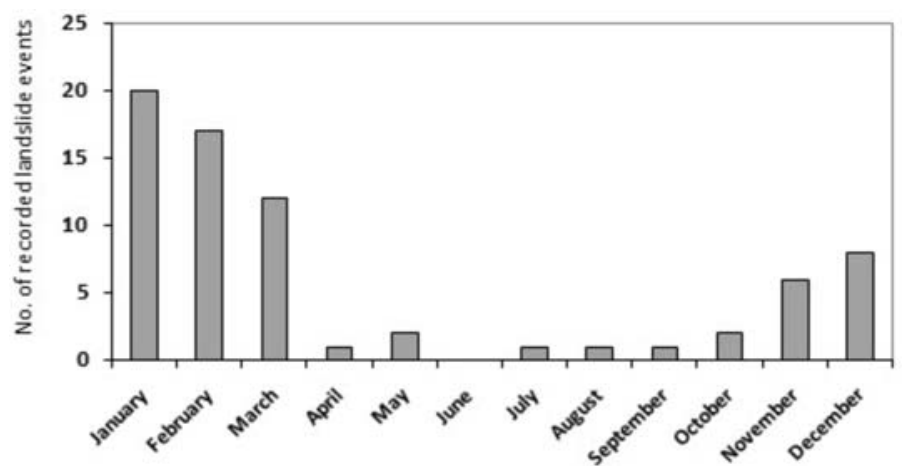

Fig. 6. Monthly distribution of recorded landslides in the period investigated.
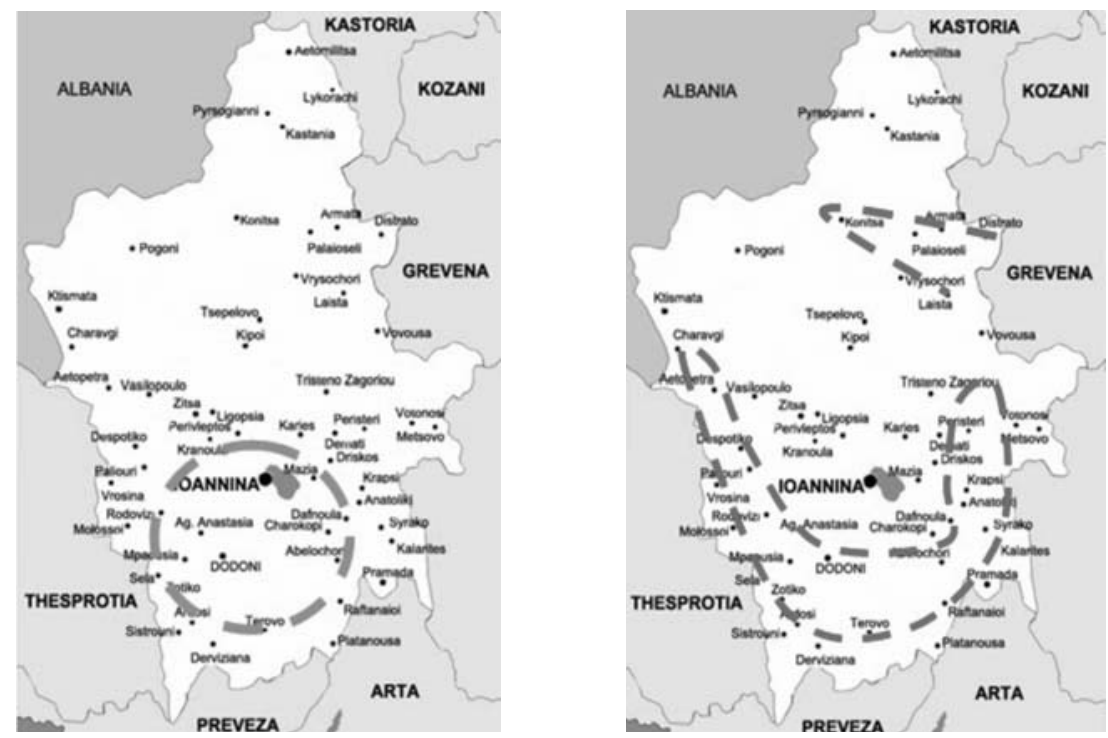

Fig.s. 7 and 8. Landslide events in regions of the Ioannina Prefecture during 1963-1966 (on the left) and 2003-2008 (on the right).

slides events in the prefecture. This information could best be presented in topographic maps.

Major landslide activity was observed during 1963-1966 (Fig.7) and 2003-2006 (Fig.8). The figure (9) represents the frequency of the landslide events related with its temporal distribution between 1963- 2008. Observations of the landslides activity during 1913-1923 are also referred by the elderly witnesses but their location and the triggering reasons remain unknown and thus any further analysis is difficult. However, overall the existence of three periods of concentration of landslides suggests repeatability of their clustering every forty years.

\subsection{Landslides' implications on the human}

The major type of infrastructure and services affected by landslides events in the prefecture of Ioannina was national roads followed by buildings. There are two recorded life losses in 1964 


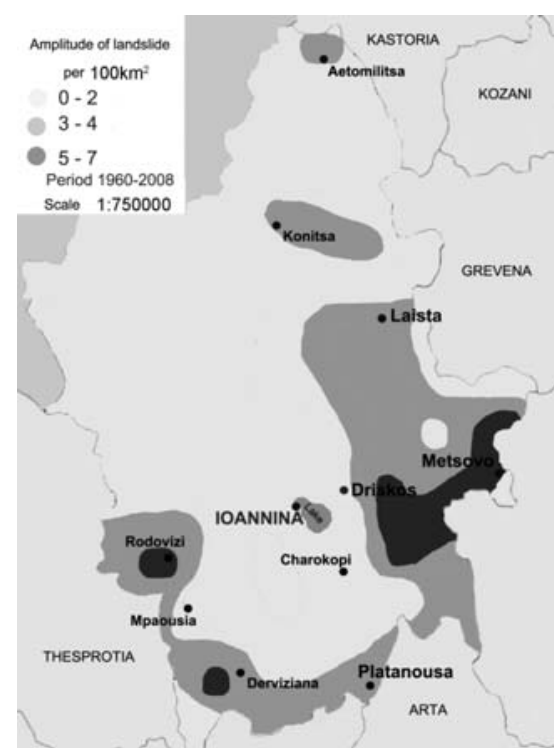

Fig. 9. The frequency of the landslide events related with its temporal distribution from between 1963-2008.

and 1996. Early press stories (1960-1970) present the landslide events with an emphasis on people's emotions rather than describing the actual event. The majority of the articles present the government's plans and actions in response to the destructive effects of the landslides, stress the amount of government subsidies to the families affected, while a great number of articles are edited by locals who are appealing to the government for help. In this early season, (19601970) reports also emphasize the causes of landslides (rain, snowfall, wind, ice, lack of trees to hold the soil) and their consequences.

The extent of press coverage of a landslide event was found to be analogous to the implications of the event for humans in the area. It was found that newspapers usually record landslides that affected people's infrastructure, and other human resources, emphasizing those large-magnitude events that occurred in urban areas or affecting roads and in those areas with press correspondents nearby. Whenever landslide events resulted in major disasters, newspapers presented reports of the events for 3-4 subsequent days in the first page. Usually, the newspaper returned to the landslide event after 8-10 days to comment on the government's actions and record the damages on properties and infrastructures due to the landslide event.

Landslides' consequences in the area's infrastructure and in the life of the locals are numerous. Articles report the accurate numbers of the families that suffered economic loses, cars destroyed, farms and places that flooded. Interestingly, there is plenty of numerical information concerning economic damages and government compensation schemes. As the majority of the landslides occurred nearby national roads, a very common consequence reported are damages in the national road infrastructure that cause delays and severe circulatory troubles.

It was also observed that between 1960 - 1970 - where the majority of landslide events occurred -, there is a considerate limited criticism to the government's measures. On the contrary, the press presents the government's response to the situation, emphasizing the compensation schemes and grants for the affected families. Gradually, the press coverage displays greater criticism to the government which appears to be inactive and neglect the situation in the area. So, while early stories rely heavily on official evaluations of the damages caused by landslides 
and reporters' sources are government representatives who arrive in the area to estimate the damage, later on reporters rely mostly on personal experiences and witnesses' stories to present the extent of the damage.

While old newspaper articles were carefully written, offering precise descriptions of the events recent story writing displays some characteristics which undermine its credibility. According to contemporary reporting trends (2000-2008) stories present vivid descriptions of the landslides events. In general, recent stories give more accurate information regarding the place and the time of the landslides, include quotes from officials, are illustrated with photos and in some cases they provide estimations about future activity or warn citizens how to cope with possible future disasters. However, in an effort to emotionalize the disaster, reporters write their stories using long sentences with a plethora of adjectives, unrealistic metaphors and active verbs. Recent articles show a lack of experience and academic background of the reporters in the description of natural hazards. Such unrealistic accounts of the situation, may lead to an overestimation of the hazard or impede our understanding of landslides phenomena.

\section{Summary and conclusion}

For the first time indexing of local and national newspapers was performed and historical data was collected about landslide events in the prefecture of Ioannina. Newspapers represented the most important source of landslide information for the period between 1963-1990 in the absence of inventories and specific technical reports.

For the period 1963-2008 eighty nine landslide events were recorded. Information on the date of the event, location, triggering mechanisms, numbers of casualties, and damages on infrastructures was obtained.

The duration of newspapers' landslide reports through time was proportional with the size of the event or its consequences on people's infrastructure and properties. Occasionally, in the newspaper articles analysis of the landslide events from geologists are included.

The collected data can be used in the construction of an inventory of historical landslide events showing their type, temporal and spatial distribution. That will provide the basis for a more comprehensive landslide hazard assessment in the prefecture of Ioannina.

As it was recorded the major disasters on properties, roads and the greatest appeal on newspapers were during 1963-1966 and 2003-2006. Furthermore, after discussion with local elderly people it was revealed that major landslide events took place from between 1913-1923. This shows a repeatability of major landslide events in the Prefecture every forty years.

\section{References}

Calcaterra, D., Parise, M., and Palma, B., 2003. Combining historical and geological data for the assessment of the landslide hazard: a case study from Campania, Italy. Nat Hazards Earth Syst Sci, 3, 3-16.

Carrara, A., Crosta, G., and Frattini, P., 2003. Geomorphological and historical data in assessing landslide hazard, Earth Surf Process Landforms, 28, 1125-1142.

Devoli, G,, Morales, A., and Høeg, K. 2007a. Historical landslides in Nicaragua-collection and analysis of data. Landslides, 4, 5-18.

Devoli, G., Strauch, W., Chávez, G., and Høeg, K., 2007b. A landslide database for Nicaragua: a tool 
for landslide-hazard management, Landslides, 4, 163-176.

Dominguez Cuesta, M.J., Jimenez Sanchez, M., Rodriguez, G.A., 1999. Press archives as temporal records of landslides in the North of Spain: relationships between rainfall and instability slope events. Geomorphology, 30, 125-132.

Doutsos, T., Koukouvelas, I.K., and Xypolias, P., 2006. A new orogenic model for the External Hellenides. In: Robertson, A.H.F. \& Mountrakis, D. (eds) Tectonic Development of the Eastern Mediterranean Region, Geol Soc Spec Publ 260, 507-520.

Doutsos, T., Koukouvelas, I., Zelilidis, A., and Kontoloulos N. 1994. Intracontinental wedging and postorogenic collapse in the Mesohellenic Trough. Geol Rund, 83, 257-275.

Guzzetti, F., Cardinali, M., Reichenbach, P. 1994. The AVI project- A bibliographical and archive inventory of landslides and floods in Italy. Environ Management, 18, 623-633.

Guzzetti, F., Cipolla, F., Lolli, O., Pagliacci, S., Sebastiani, C.,Tonelli, G., 2002. Information system on historical landslides and floods in Italy. Urban Hazards Forum. John Jay College, CUNY, New York.

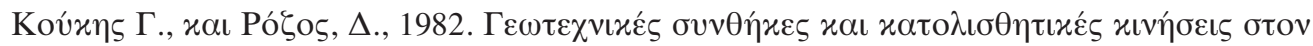

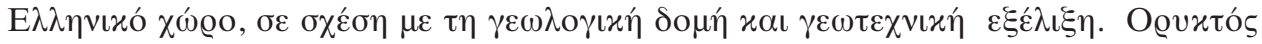

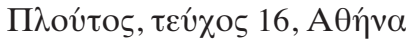

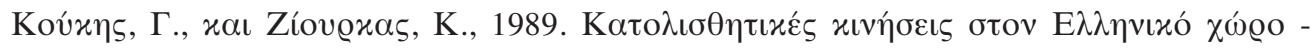

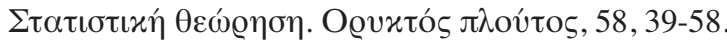

Koukis, G., 1988. Slope deformation phenomena related to the engineering geological conditions in Greece. Proceedings 5th Inter. Symp. on Landslides, 2, 1187-1192.

Koukis, G., Ziourkas, K., 1991. Slope instability phenomena in Greece. A statistical analysis. Bulletin of the Int. Assoc. of Engineering Geology, 43, 47-60.

Koukis, G., Tsiambaos, G., Sabatakakis, N., 1994. Slope movements in the Greek territory: A statistical approach. Proceedings $7^{\text {th }}$ International Congress, IAEG, 4621-4628, Lisboa-Portugal.

Koukis, G., Tsiambaos, G., Sabatakakis, N., 1996. Landslides in Greece: Research, evolution and quantitative analysis. Proceedings $7^{\text {th }}$ International Symposium on Landslides, 1935-1940, Trondhein, Norway.

Koukis, G., Rozos, D., Hatzinakos, I., 1996. Rainfall induced landslides in Achaia county, Greece. Proc. of International Congress of I.A.E.G., A. A. Balkema, Vol. III, pp 1929-1934, Norway.

Koukis, G., Rozos, D., Hatzinakos, I., 1997. Relationship between rainfall and landslides in the formations of Achaia county, Greece. Proc. of International Symposium of I.A.E.G. in Engineering Geology and the Environment, A.A. Balkema, Vol.1, pp.793-798, Iov́vıos 1997. Rotterdam.

Sawyer, C., Butler, D., 2006. A chronology of high-magnitude snow avalanches reconstructed from archived newspapers. Disaster Prevention and Management, 15, 313-324.

Tarhule, A., 2005. Damaging rainfall and flooding: The other Sahel hazards. Climatic change, 72 , 355-377.

Tropeano, D., Turconi, L., 2004 . Using Historical Documents for Landslide, Debris Flow and Stream Flood Prevention. Applications in Northern Italy, Natural Hazards, 31, 663-679.

Wrathall, J., 2007. Natural Hazard Reporting in the UK Press. Disasters, 12, 177-182.

Xypolias, P., and Koukouvelas, I.K., 2005. Paleostress magnitude in a Fold-Thrust Belt (External Hellenides, Greece): evidence from twinning in calcareous rocks. Episodes, 28, 245-251.

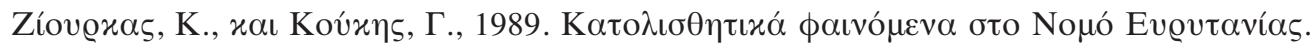

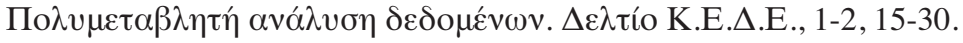




\section{$\underline{\text { Internet }}$}

www.epirus.gov.gr

www.hnms.gr

http://medlab.cs.uoi.gr

http://www.ntua.gr/MIRC/db /epirus_db/GEOLOGIA_HPEIROY/Geologia_Hpeirou.htm

Newspapers

Eleftheria

Eleftherotipia

Ethnos

Hpeirotikos Agonas

Kathimerini

Proinos Logos

Rizospastis

Ta Nea

To Vima 